\title{
Pediatric surgery for childhood cancer: Lasting experiences and needs of children and parents
}

Short running title: impact of surgery for pediatric cancer

Mark G Gabriel, , b Claire E Wakefield, ${ }^{\mathrm{a}, \mathrm{b}}$ Janine Vetsch, ${ }^{\mathrm{a}, \mathrm{b}}$ Jonathan S Karpelowsky, ${ }^{\mathrm{c}, \mathrm{d}, \mathrm{e}}$ Anne-Sophie E Darlington, ${ }^{\mathrm{f}}$ Richard J Cohn, ${ }^{\text {a, b }}$ Christina Signorelli ${ }^{a, b}$

Affiliations:

on behalf of the ANZCHOG Survivorship Study Group*

a School of Women's and Children's Health, UNSW Sydney, , Australia, b Kids Cancer Centre, Sydney

Children's Hospital, Randwick, NSW, Australia, c Department of Paediatric Surgery, Children's Hospital

Westmead d Children's Cancer Research Unit, Kids Research Institute, Sydney e Division of Child and

Adolescent Health University of Sydney, ${ }^{\mathrm{f}}$ Faculty of Health Sciences, University of Southampton, UK.

*ANZCHOG survivorship study group: The members of the ANZCHOG Survivorship Study Group in alphabetical order: Dr Frank Alvaro, Prof Richard Cohn, Dr Rob Corbett, Dr Peter Downie, Ms Karen Egan, Ms

Sarah Ellis, Prof Jon Emery, Dr Joanna Fardell, Ms Tali Foreman, Dr Melissa Gabriel, Prof Afaf Girgis, Ms Kerrie

Graham, Ms Karen Johnston, Dr Janelle Jones, Dr Liane Lockwood, Dr Ann Maguire, Dr Maria McCarthy, Dr

Jordana McLoone, Dr Francoise Mechinaud, Ms Sinead Molloy, Ms Lyndal Moore, Dr Michael Osborn, Dr

Christina Signorelli, Dr Jane Skeen, Dr Heather Tapp, Ms Tracy Till, Ms Jo Truscott, Ms Kate Turpin, Prof Claire

Wakefield, Ms Jane Williamson, Dr Thomas Walwyn, and Ms Kathy Yallop.

Corresponding author: Dr Christina Signorelli, Kids Cancer Centre, Sydney Children's Hospital, High St,

Randwick, NSW 2031, Australia. T: +61-2-9382-5563, F: +61-2-9382-1789, E: c.signorelli@unsw.edu.au

Key words: psychosocial; children; parents; surgery; pediatric cancer

Abstract Word Count: 248

Manuscript word count: 3,495

Number of Tables/figures: 4

Supplementary Tables/figures: 1

List of abbreviations: Nil

Acknowledgements: We would like to thank Dr Kate Hetherington, Dr Janine Vetsch, Brittany McGill, Mary-Ellen Brierley, Daisy Collins and Luke Fry who conducted interviews. We would also like to thank the families who participated and each of the recruiting sites for this study, including Sydney Children's Hospital Randwick, the Children's Hospital at Westmead, John Hunter Children's Hospital, the Royal Children's Hospital Melbourne, Monash Children's Hospital Melbourne, Royal Children's Hospital Brisbane, Princess Margaret Children's

This is the author manuscript accepted for publication and has undergone full peer review but has not been through the copyediting, typesetting, pagination and proofreading process, which may lead to differences between this version and the Version of Record. Please cite this article as doi: $\underline{10.1111 / \text { ECC. } 13116}$

This article is protected by copyright. All rights reserved 
Hospital, Women's and Children's Hospital Adelaide, and in New Zealand, Starship Children's Health, Wellington Hospital and Christchurch hospital.

Conflict of Interest: The authors declare that they have no conflict of interest.



Funding: The Behavioural Sciences Unit is proudly supported by the Kids with Cancer Foundation, and its survivorship program is funded by a Cancer Council NSW Program Grant (PG16-02) with the support of the Estate of the Late Harry McPaul. Christina Signorelli is supported by The Kids' Cancer Project. Claire Wakefield is supported by a Career Development Fellowship from the NHMRC of Australia (APP1067501). The sponsors were not involved in the study, writing this manuscript or the decision to submit the manuscript for publication.






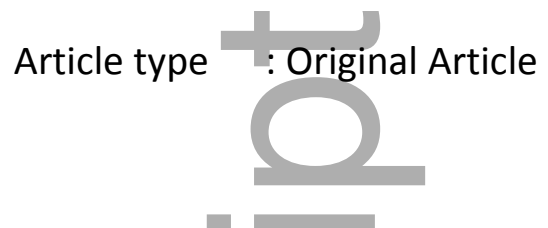

\begin{abstract}
Objective: Surgery for pediatric cancer presents many stresses on patients and families. The authors aimed to understand the long-term impact of childhood cancer surgery on survivors and parents.
\end{abstract}

Methods: The study recruited participants from 11 Australia/New Zealand hospitals for telephone interviews. The authors used descriptive statistics to analyse participants' quantitative distress ratings and conducted thematic analysis of shared surgical experiences and needs.

Results: Of 32 participants ( $\mathrm{n}=17$ survivors, $\mathrm{n}=15$ parents), survivors' mean age at surgery was $6.9(\mathrm{SD}=5.17)$ and parents' children were 2.1 years old $(\mathrm{SD}=1.41)$ at time of surgery. Survivors had surgery on average 15.2 years ago $(\mathrm{SD}=6.72)$ and parents' children 11.5 years ago $(\mathrm{SD}=3.94)$. Parents and survivors rated surgery as highly distressing. Preoperatively, survivors recalled experiencing fear and pain mainly associated with preoperative procedures. Postoperatively, survivors reported immobility and some lasting behavioral disturbances. Parents described pre- and intraoperative anxiety and stress and some lasting postoperative psychological disturbances. Experiences appeared to improve with clear/consistent communication from hospital staff, proximity to hospital, and with support for parents and children postoperatively.

Conclusions: Surgical treatment for childhood cancer can have a lasting impact for survivors and parents. Better information provision may improve families' surgical experience whilst reducing anxiety, distress and physical discomfort.

\title{
INTRODUCTION
}

Having surgery can be challenging at any age. The disruption of daily life, temporary immobility, and unfamiliar environment can cause anxiety in the lead up to surgery. The added prospects of invasive procedures, pain and risk of complications only increase the difficulties that define the surgical experience (Kerper et al., 2012). Patients commonly report increased anxiety, stress, and depression throughout the perioperative period (Kerper et al., 2012). These can be exacerbated by patients' doubts concerning potential surgical outcomes and implications for their future health, activities of daily living and quality of life (Lisboa Gois et al., 2012).

The challenges of surgery are exacerbated when the patient is a child. Children undergoing surgery can experience lasting impressions of surgery, dependent on their age and stage of cognitive development (Anderson, 2002). Pediatric patients range from younger, less aware, and highly attached children, to older children and adolescents who may have an increasingly comprehensive understanding of their condition. Children's psychosocial experiences differ according to surgical procedures and conditions, such as cardiac or orthopaedic surgery and can be 
linked with the physical consequences of surgery (such as decreased general health)(Jonovska et al., 2008) and the disruptive surgical experience (such as anxiety and depression (Papakostas et al., 2003), and behavioral disturbances).(Williams et al., 2015) Parents often share many of their child's fears and concerns during surgery and can experience anxiety, exhaustion and, as reported in some parents of children undergoing cardiac surgery, may experience stress worthy of a diagnosis of acute stress disorder (Melamed and Ridley-Johnson, 1988, Franich-Ray et al., 2013).

Pediatric surgery is further intensified in the setting of childhood cancer (McArdle et al., 1996, Zeltzer et al., 2009). The complex pathogenesis, morbidity and rigorous treatment of childhood cancer can create a high level of concern and distress in young cancer patients and their families (Fallowfield et al., 1986). Surgery is commonly indicated in cancer patients where the surgical resection of a tumor is required (Grimm et al., 2014, Coffey et al., 2003). Surgery is also used to aid in the diagnosis, staging and grading of tumors (Enneking et al., 1980). Cancerrelated operations can be invasive and may involve substantial medical risk. Adult cancer patients have reported ongoing pain, stress, depression and difficulty coping with their surgical consequences postoperatively (GoldenKreutz and Andersen, 2004, Handy et al., 2002, Poleshuck et al., 2006). Children and adolescents may have some understanding of their disease, but have limited experience of the health system and less well-developed coping strategies than their adult counterparts (Folkman et al., 1987), thus making them potentially less well-equipped for the difficult realities of cancer surgery.

It is clear that children undergoing non-cancer-related surgery require healthcare assistance, staff services,(Thompson and Tielsch-Goddard, 2014) and practical support such as social work and family accommodation throughout the operative period (Williams et al., 2015). Parents of children undergoing a variety of operations have described the benefits of surgery-specific information and support services in order to cope better during the perioperative period (Iversen et al., 2009). While this data is valuable, no study has assessed the psychosocial experiences or needs of pediatric patients undergoing surgery for cancer specifically (Gabriel et al., 2017). The experiences and needs of parents of children undergoing surgery for cancer also remain unexplained. This is an important gap given that many thousands of children have cancer-related operations each year worldwide (Ward et al., 2014). This study therefore aimed to evaluate the lasting impact of pediatric cancer surgery by exploring survivors' and parents' long-term recollections of surgery for cancer to provide a better standard of care.

There were two key research questions: 1) what are long-term childhood cancer survivors' and parents of young survivors' psychosocial experiences of surgery? 2) what are the needs (e.g. information, service, support needs) of young patients and parents during the pre-, intra-, and postoperative periods?

\section{METHODS}

Participants

Eligible survivors and parents were invited to participate in the Australia and New Zealand Children's Haematology/Oncology Group (ANZCHOG) Survivorship Study survey (Michel et al., 2016). Long-term survivors were eligible if they: 1) had been diagnosed with cancer prior to turning 16 years of age at least 5 years before their participation in the study, 2) had undergone and completed cancer treatment at one of eleven participating hospitals, 3) could speak English, and 4) were in full remission. The authors contacted survivors for interviews if they underwent surgery as part of their cancer treatment (including portacaths and tumor resections), identified in surveys. Ethics approval was obtained from participating hospitals and informed consent received from all participants. 
Data collection

After identifying eligible participants through hospital records, the authors sent surveys to potential participants. Participants reported their demographic and clinical details in the survey. Participants were invited in the survey to participate in an optional semi-structured telephone interview. Survivors over 16 years of age completed interviews themselves. For survivors under 16 years, their parent/guardian completed a parent-modified version of the interview. A multidisciplinary team comprising a pediatric surgeon, oncologist, clinical psychologists, and researchers developed the interview guide (Supplementary Table 1), pilot-tested with three survivors before study commencement. Trained psychosocial researchers conducted semi-structured telephone interviews with participants, none of whom had any prior relationships. Interview questions related to the nature of their (child's) surgery, satisfaction with the surgery, and experiences and needs throughout surgical periods (before: preoperative, during: intraoperative and after: postoperative). Participants were asked to rate how distressing: 1) the initial diagnosis, 2) the surgery, and 3) their combined cancer therapy was for themselves and for their parents/children on a scale of 1 ("not at all' distressing) to 10 ('extremely' distressing).

Data analysis

The authors used SPSS24.0 for descriptive statistics of demographic survey data and participants' distress ratings. Interviews were audio-recorded and transcribed verbatim. The authors implemented deductive thematic analysis to examine and understand the experiences and needs of survivors using NVivo11, which was guided by the Braun \& Clarke framework (Braun and Clarke, 2006). In line with this approach, two researchers (MG, CS) developed a coding tree based on overarching themes and categories derived from our research questions and semi-structured interview script (Supplementary Table 2). Minor categories were developed in developed both in advance and inductively during the coding process. The researchers coded $10 \%$ of interviews line-by-line to 'test' the coding tree (97.95\% agreement) and resolved differences through discussion. Given high agreement, the remainder of interviews were coded line-by-line by one researcher (MG). Participant's overall experiences were coded as either positive, neutral or negative based on their general perspective conveyed in relevant questions. The researchers categorized participants' responses according to time period (pre-, intra-, and postoperative) to facilitate the identification of common experiences and needs across the surgical trajectory (Table 1). The researchers analysed data concurrently with data collection, until reaching data saturation of our key themes (Miles and Huberman, 1984).

\section{RESULTS}

Of 46 eligible participants, 32 participants were interviewed (Figure 1): 17 survivors (mean age at study: 23.4 years; Table 2) and 15 parents (child mean age at study: 15.1 years). All survivors underwent major surgery (i.e. tumor resection), and $34 \%$ also reported minor operations (e.g. Portacath implantation). Survivors' operations were on average 15.18 years ago $(S D=6.72)$, performed when they were on average 6.88 years old $(\mathrm{SD}=5.17)$. Parents were interviewed on the operations of their children who were on average 2.13 years old $(\mathrm{SD}=1.41)$ at surgery, on average 11.47 years ago $(\mathrm{SD}=3.94)$.

Fifty-six percent of participants were satisfied with their overall experience of surgery, however largely described their overall experiences of surgery as challenging. Overall parents reported higher distress ratings than survivors (Figures $2 \mathrm{~A}$ and $2 \mathrm{~B})$. Survivors rated their surgery alone as less distressing (6.0, SD=2.24) than the combination of treatments $(7.0, \mathrm{SD}=2.07)$ and perceived their parents' experiences of these periods to have been more distressing than their own, which closely matched their parents' self-reported experiences $(8.1, \mathrm{SD}=1.89$ versus 8.8 , 
$\mathrm{SD}=1.69$ respectively). Qualitatively, survivors primarily described preoperative fear and pain associated with preoperative procedures. Parents commonly reported feelings of helplessness, anxiety and fear and described unmet information needs about surgery and inadequate support from hospital staff. Survivors and parents appeared to describe less distress if they had few unmet support and information needs.

\section{Survivors' preoperative experiences and needs}

Preoperative experiences and needs amongst survivors and parents revolved around preparing for surgery. Fear of imminent surgical pain and painful preoperative tests worried and frightened some children, who felt intimidated and inadequately prepared: "I just couldn't stop screaming. All the doctors had to hold me down" (female non-Hodgkin's lymphoma survivor, aged 9 at diagnosis). Other survivors described more positive preoperative experiences which they attributed to family support, and friendly and attentive hospital staff. Many survivors described a desire for a less frightening hospital experience, citing their unfamiliarity with its sights, sounds, equipment and procedures but gave few specific details, citing their young age at the time of the surgery (some of whom were months old). Others recalled preoperative experiences as beneficial, viewing their good health in the present day as indicators of sufficiently met preoperative needs, reporting feeling "very satisfied, I guess, because I'm fine now" (female nonHodgkin's lymphoma survivor, aged 9 at diagnosis).

\section{Parents' preoperative experiences and needs}

Many parents experienced distress in the preoperative period. Parents of children operated in a short time described the rushed nature of the preoperative period where "they'll wheel her out of one [test] and then throw her into another... she was just beside herself" (father of Medulloblastoma survivor aged 3 at diagnosis). Preoperative stress appeared related to parents' perceived life-threatening nature of the surgery, amplified for some who described a lack of personal interaction from hospital staff towards their children who would view patients "like she was just an interesting case to look at" (mother of Neuroblastoma survivor, aged 1 at diagnosis). Some parents described a lack of understandable information while others, whose information needs were met by "clear... blow by blow" (mother of Hepatoblastoma survivor aged 1 at diagnosis) accounts of their child's upcoming surgery in written or verbal formats, reported greater preoperative satisfaction with "fantastic" hospital staff (mother of Hepatobastoma survivor aged 1 at diagnosis). Rural parents described their often rapid move from their distant homes at the time of surgery as "probably the hardest thing [about the surgery]" (father of Medulloblastoma survivor aged 3 at diagnosis). Parents who were provided accommodation and support from social workers and other services appeared more satisfied and reassured entering the intraoperative period.

\section{Parents' intraoperative experiences and needs}

The duration of time parents were under anaesthetic away from their parents ranged from 2 to 20 hours. Most parents recalled difficult experiences associated with the lengthy duration of the intraoperative period after finding it "really difficult to say goodbye" (mother of Brain cancer survivor aged 2 at diagnosis). Parents made a variety of choices regarding how to spend their time whilst waiting for surgery completion. Sixty-seven percent of parents remained in the hospital during their child's surgery. Some described distressing triggers in the hospital environment (e.g. distressed families, upsetting televised news) and physical symptoms (e.g. migraines, headaches) as a result of the "intense frustration of not being able to be in control of helping your own child" (father of Hepatoblastoma survivor aged 2 at diagnosis). Parents who temporarily left the hospital appeared to report less intraoperative anxiety, crediting 
accompanying supports (e.g. spouse, friend, volunteer) as integral to their decision to do so. Parents described their need for supportive services during the intraoperative period, which for some was "too dark and too hard on your own" (mother of Medulloblastoma survivor, aged 3 at diagnosis). Some parents described feeling alienated by some staff who were "not warm and fuzzy" (mother of Medulloblastoma survivor aged 3 at diagnosis) while others described acts of generosity ranging from a cup of tea to counselling from social workers which helped alleviate their stresses. Parents outlined the need for more intraoperative communication, describing it as "a black tunnel" (father of Hepatoblastoma survivor, aged 2 at diagnosis) where some were left "imagining all these horrible things that are happening” (mother of Retinoblastoma survivor, aged 1 at diagnosis). Some parents described receiving a large amount of information which adversely affected them, however parents who felt adequately informed during surgery appeared to have more positive intraoperative experiences and recommended "more open communication" (mother of Retinoblastoma survivor, aged 1 at diagnosis) during surgery to help cope.

Survivors' postoperative experiences and needs

Survivors recalled experiencing pain, vomiting, immobility and some behavioral disturbances following surgery causing fears associated with the hospital environment. Sometimes procedural anxiety was long-lasting, reexperienced by adult survivors who needed surgery many years later or were in non-medical yet similarly stressful situations. One adult survivor reported that she:

“...developed a very very severe fear to injections. I have quite a few vivid memories, kind of like video clips in your head, where I was being held down for injections then...I'd go to sleep and I'd wake up and I'd be in pain somewhere." (female Neuroblastoma survivor, aged 1 at diagnosis).

Some parents perceived that their child's postoperative distress caused behavioral disturbances like difficulty separating from parents, panic, dissociation and in some few cases, temporary selective mutism in survivors who "just wouldn't speak" (father of Medulloblastoma survivor, aged 3 at diagnosis). While some parents perceived the postoperative behavioral disturbances of their children as a sign of anxiety and depression, a few survivors themselves described some positive postoperative experiences related to the personal, supportive and ongoing postoperative care they received from hospital staff who assisted in what many described as unavoidable consequences of surgery. Most survivors described requiring assistance in mobilization and comfort following surgery, which for many was appropriately met by hospital staff. Survivors credited hospital staff who met their physical needs both in the postoperative period and longer into their long-term care.

\section{Parents' postoperative experiences and needs}

Some parents reported feelings of helplessness and unease postoperatively leading to psychological impacts such as insomnia, depression and anxiety. Many parents described concern over pending surgical outcomes which "was actually more gut wrenching than the initial diagnosis" (mother of Hepatoblastoma survivor aged 1 at diagnosis). Such thought processes, attributed to ambiguous information from hospital staff, have been long-lasting for some parents who suspect "something is still wrong" (mother of survivor, aged 1 at diagnosis). Parents described being able to process their fears and concerns in the less-rushed postoperative period, having "been through a war and you've been traumatized" (father of Pleuropulmonary Blastoma survivor, aged 3 at diagnosis). The traumatic impact of surgery was evident for another parent who "still... take[s] a really tiny dose of [a sleeping tablet]" (mother of Hepatoblastoma survivor, aged 1 at diagnosis, having commenced medication postoperatively. Parents struggled with their postoperative roles as carers, particularly parents of brain tumor survivors (30\%) who were "quite disabled [and] 
couldn't do anything so there was a lot of lifting and shifting and carrying and holding”" (mother Brain cancer of survivor, aged 2 at diagnosis). Parents suggested more assistance to better manage their child's postoperative pain due the difficulty of administering medication but credited physiotherapists, occupational and speech therapists in their child's long-term recovery, particularly in “learn[ing] to walk, talk and balance..." (mother of Brain cancer survivor, aged 2 at diagnosis).

\section{DISCUSSION}

Seventeen long-term survivors and 15 parents of survivors of took part in interviews regarding their experiences and needs regarding surgery for childhood cancer. Preoperatively, survivors recalled experiencing discomfort and a fear of the hospital environment and described needing more familiarity with their surroundings and postoperatively most commonly reported pain. Parents described higher distress ratings across all time periods than survivors, likely since parents were the primary carers (Svavarsdottir, 2005). Parents described heightened feelings of distress, anxiety, and helplessness before and during their child's surgery and psychological impacts afterwards. Parents described a need for more information before surgery, increased communication during surgery, and postoperative support from hospital staff regarding their child's mobilization and recovery. When these needs were met, parents and survivors appeared to report more positive experiences.

Children describe negative experiences associated with uncomfortable, unfamiliar and traumatizing preoperative tests as documented in several studies over many decades (Brewer et al., 2006, Corman et al., 1958, Pearson, 1941, Vernon, 1965). Many survivors who underwent treatment prior to surgery experienced increased physical discomfort preoperatively, consistent with findings amongst adolescent cancer patients (Walker et al., 2010). Survivors and parents who underwent adjuvant treatment reported higher distress ratings and may have additional support and information needs. Families who were faced with emergency surgery after a cancer diagnoses experienced additional shock and fear, given the unexpected nature of a pediatric cancer diagnosis (Wong and Chan, 2006). Future research should be conducted with cancer patients closer to the time of surgery when surgical experiences and needs are likely to be better remembered, allowing for future targeted preoperative interventions like familiarising children to their hospital environments. Parents who received sufficient information regarding their child's upcoming surgery appeared to recount more positive preoperative experiences. Some parents reported unmet preoperative information needs about surgery which cannot always be met, given the difficulty of predicting surgical outcomes (Wakefield et al., 2012). Parents who expressed satisfaction with hospital staff engagement recounted more positive preoperative experiences, consistent with parents' needs for passionate and sensitive hospital staff using open and patient-centered communication (Ygge and Arnetz, 2004, Homer et al., 1999). Parents of survivors appeared to prefer written and verbal information, however more investigation is needed to understand their preferences in the context of surgery (Vetsch et al., 2015). Rural parents reported initial challenges due to the large distance between their homes and hospital. Nonetheless, the rural parents who participated complimented the hospital-affiliated accommodation services available to them which had a positive effect on their wellbeing, as reported in other studies (Taylor and O'Connor, 1989, Daniel et al., 2013).

Pre- and intraoperative experiences and needs appeared to influence survivors' long-term outcomes. Intraoperative communication has been shown in parents of children undergoing surgery for congenital heart disease to be an important predictor of parents' overall satisfaction with their experiences regardless of the physical outcome of surgery (Wei et al.). Providing sufficient information to parents where requested, may also reduce long-term psychological sequelae although this may not always be possible (Franich-Ray et al., 2013). Parents who were 
satisfied with hospital staff communication reported more positive intraoperative experiences while other parents described having an excess of overwhelming medical details and information (Hummelinck and Pollock, 2006). Consistently engaging with parents whilst gauging their desire for and ability to comprehend medical details is a recommended approach to meeting parents' intraoperative needs, maintaining their relationships with hospital staff, and improving their surgical experiences (Levetown, 2008, Michel et al., 2016). Parents used coping strategies such as leaving the hospital environment during their child's surgery in order to alleviate their stress, also reported as a useful tactic among parents of adolescents undergoing spinal surgery (Salisbury et al., 2007). Parents who remained in the hospital during their child's surgery for cancer experienced increased instances of anxiety and distress, therefore suggestive of an association between the two. Parents' decision to leave hospital could have been influenced by personal methods of coping, levels support or seriousness of operations requiring further investigation of targeted strategies. Providing nearby options for all parents to spend their time during their child's surgery may alleviate some intraoperative stress.

For some survivors, the disruption and discomfort experienced as a result of surgery caused longstanding procedural anxiety, triggered by hospital environments and staff. Survivors who described greater pain, immobility and complications following surgery experienced behavioral and psychological impacts to a greater degree than those who did not, reflected by the findings of a recent review of 50 studies (Pinto et al., 2016). Pediatric patients who become traumatized by hospital environments are less likely to access health care services, potentially delaying required treatment in the future (Lerwick, 2016). It is crucial that survivors with increased experiences of pain and immobility are provided with specific care and assistance tailored to their needs in order to allow them to comfortably access long-term follow-up care required. Many parents who experienced anxiety and distress in the pre and intraoperative periods developed long-lasting psychological impacts in the postoperative period, also experienced by parents of children undergoing cardiac surgery (Harvey et al., 2013). Monitoring parents' preoperative and intraoperative wellbeing and identifying distressed parents (through routine questionnaires and screening incorporated into their child's routine care) may assist in preventing the development of these prolonged postoperative psychological impacts, thus improving parents' long-term well-being ( $\mathrm{Li}$ and Lam, 2003).

The time lapsed between participant's surgery and study participation is a limitation to this study, particularly regarding the accuracy of specific details such as surgery duration. Nonetheless, participants' ability to recall vivid memories up to 27 years after surgery also highlights the pertinence of these issues, the profoundness of their experiences and potential psychological burden carried as a result. It may also be important to further evaluate how patients and parents more broadly cope with the long-term effects of their cancer surgical care. Whilst interview questions were specifically asked in relation to surgery it is possible participants' recounted experiences of their entire cancer or treatment experience, rather than surgery alone. Given surgery is commonly required in conjunction with (neo)adjuvant therapy in pediatrics future research would be valuable in surgical participants who have not yet undergone adjuvant therapies or more directly comparing the experiences of those who have had surgery alone to those who have had a combination of treatments. Participants' young age at surgery or remission from cancer may have positively skewed their perceived surgical experiences. It may be valuable to consider perspectives of those who have not experienced remission for a more balanced understanding of surgical experiences and needs. Approaches to surgery and supportive care are likely to have changed since these operations were done. Potential biases inherent to interview-based qualitative data collection were minimized through bracketing, journal keeping, regular meetings with a multidisciplinary team, and overlapping of data coding and analysis by two researchers (MG, CS). 
Childhood cancer survivors and parents recalled an array of psychological, behavioral and physical disturbances during the pre-, intra- and postoperative periods for childhood cancer. The data suggests that increased communication from hospital staff in the hospital during the preoperative and intraoperative periods could be implemented in order to identify and assist particularly distressed children and parents and provide them with the information and support that they need. These measures are important given the potentially long-lasting psychological effects of surgical treatment for cancer, experienced by young survivors and parents following surgery. Whilst surgery for pediatric cancer has undeniable challenges for patients and parents, more can still be done to meet their needs and improve their long-term psychosocial outcomes. Future research may be valuable with families during the time of surgery (or shortly after) or among those who have experienced only surgical treatment to better understand and improve surgical experiences.

\section{REFERENCES}

ANDERSON, P. 2002. Assessment and development of executive function (EF) during childhood. Child neuropsychology, $8,71-82$.

BRAUN, V. \& CLARKE, V. 2006. Using thematic analysis in psychology. Qualitative Research in Psychology, 3, 77-101.

BREWER, S., GLEDITSCH, S. L., SYBLIK, D., TIETJENS, M. E. \& VACIK, H. W. 2006. Pediatric Anxiety: Child Life Intervention in Day Surgery. Journal of Pediatric Nursing, 21, 13-22.

COFFEY, J. C., WANG, J., SMITH, M., BOUCHIER-HAYES, D., COTTER, T. \& REDMOND, H. 2003. Excisional surgery for cancer cure: therapy at a cost. The lancet oncology, 4, 760-768.

CORMAN, H. H., HORNICK, E. J., KRITCHMAN, M. \& TERESTMAN, N. 1958. Emotional reactions of surgical patients to hospitalization, anesthesia and surgery. The American Journal of Surgery, 96, 646-653.

DANIEL, G., WAKEFIELD, C., RYAN, B., FLEMING, C., LEVETT, N. \& COHN, R. 2013. Accommodation in pediatric oncology: parental experiences, preferences and unmet needs. Rural and remote health, 13 .

ENNEKING, W. F., SPANIER, S. S. \& GOODMAN, M. A. 1980. A system for the surgical staging of musculoskeletal sarcoma. Clinical orthopaedics and related research, 153, 106-120.

FALLOWFIELD, L. J., BAUM, M. \& MAGUIRE, G. 1986. Effects of breast conservation on psychological morbidity associated with diagnosis and treatment of early breast cancer. Br Med J (Clin Res Ed), 293, 1331-1334.

FOLKMAN, S., LAZARUS, R. S., PIMLEY, S. \& NOVACEK, J. 1987. Age differences in stress and coping processes. Psychology and aging, 2, 171.

FRANICH-RAY, C., BRIGHT, M. A., ANDERSON, V., NORTHAM, E., COCHRANE, A., MENAHEM, S. \& JORDAN, B. 2013. Trauma reactions in mothers and fathers after their infant's cardiac surgery. Journal of pediatric psychology, jst015.

GABRIEL, M. G., WAKEFIELD, C. E., VETSCH, J., KARPELOWSKY, J. S., DARLINGTON, A.-S. E., GRANT, D. M. \& SIGNORELLI, C. 2017. The Psychosocial Experiences and Needs of Children Undergoing Surgery and Their Parents: A Systematic Review. Journal of Pediatric Health Care. 
GOLDEN-KREUTZ, D. M. \& ANDERSEN, B. L. 2004. Depressive symptoms after breast cancer surgery: Relationships with global, cancer-related, and life event stress. Psycho-Oncology, 13, 211-220.

GRIMM, J. C., VALERO, V. \& MOLENA, D. 2014. Surgical indications and optimization of patients for resectable esophageal malignancies. Journal of Thoracic Disease, 6, 249-257.

HANDY, J. J. R., ASAPH, J. W., SKOKAN, L., REED, C. E., KOH, S., BROOKS, G., DOUVILLE, E. C., TSEN, A. C., OTT, G. Y. \& SILVESTRI, G. A. 2002. What happens to patients undergoing lung cancer surgery?*: Outcomes and quality of life before and after surgery. Chest, 122, 21-30.

HARVEY, K. A., KOVALESKY, A., WOODS, R. K. \& LOAN, L. A. 2013. Experiences of mothers of infants with congenital heart disease before, during, and after complex cardiac surgery. Heart \& Lung: The Journal of Acute and Critical Care, 42, 399-406.

HOMER, C. J., MARINO, B., CLEARY, P. D. \& ET AL. 1999. Quality of care at a children's hospital: The parents' perspective. Archives of Pediatrics \& Adolescent Medicine, 153, 1123-1129.

HUMMELINCK, A. \& POLLOCK, K. 2006. Parents' information needs about the treatment of their chronically ill child: A qualitative study. Patient Education and Counseling, 62, 228-234.

IVERSEN, A. S., GRAUE, M. \& CLARE, J. 2009. Parents' Perspectives of Surgery for a Child Who Has Cerebral Palsy. Journal of Pediatric Health Care, 23, 165-172.

JONOVSKA, S., JENGIC, V. S., KVESIC, A., PAVLOVIC, E., ZUPANCIC, B., GALIC, G., KLARIC, M. \& KLARIC, B. 2008. The quality of life during the treatment of long bone fractures in children and adolescents. Coll Antropol, 32, 1121-7.

KERPER, L. F., SPIES, C. D., LÖßNER, M., SALZ, A.-L., TAFELSKI, S., BALZER, F., WEIßGERLACH, E., NEUMANN, T., LAU, A., GLAESMER, H., BRÄHLER, E. \& KRAMPE, H. 2012. Persistence of Psychological Distress in Surgical Patients with Interest in Psychotherapy: Results of a 6-Month Follow-Up. PLOS ONE, 7, e51167.

LERWICK, J. L. 2016. Minimizing pediatric healthcare-induced anxiety and trauma. World journal of clinical pediatrics, 5,143 .

LEVETOWN, M. 2008. Communicating With Children and Families: From Everyday Interactions to Skill in Conveying Distressing Information. Pediatrics, 121, e1441-e1460.

LI, H. C. W. \& LAM, H. Y. A. 2003. Paediatric day surgery: impact on Hong Kong Chinese children and their parents. Journal of Clinical Nursing, 12, 882-887.

LISBOA GOIS, C. F., MAIMONI AGUILLAR, DOS SANTOS, V. \& LLAPA RODRÍGUEZ, E. O. 2012. Stress factors for patients undergoing cardiac surgery. Investigación y Educación en Enfermería, 30, 312-319.

MCARDLE, J. M. C., GEORGE, W. D., MCARDLE, C. S., SMITH, D. C., MOODIE, A. R., HUGHSON, A. V. M. \& MURRAY, G. D. 1996. Psychological support for patients undergoing breast cancer surgery: a randomised study. BMJ, 312, 813-816.

MELAMED, B. G. \& RIDLEY-JOHNSON, R. 1988. Psychological Preparation of Families for Hospitalization. Journal of Developmental \& Behavioral Pediatrics, 9, 96-102. 
MICHEL, G., GIANINAZZI, M., EISER, C., BERGSTRAESSER, E., VETSCH, J., WEID, N. \& KUEHNI, C. 2016. Preferences for long- term follow- up care in childhood cancer survivors. European journal of cancer care, 25, 1024-1033.

MILES, M. B. \& HUBERMAN, A. M. 1984. Qualitative data analysis: a sourcebook of new methods, Sage Publications.

PAPAKOSTAS, K., MORAITIS, D., LANCASTER, J. \& MCCORMICK, M. S. 2003. Depressive symptoms in children after tonsillectomy. International Journal of Pediatric Otorhinolaryngology, $67,127-132$.

PEARSON, G. H. 1941. Effect of operative procedures on the emotional life of the child. American Journal of Diseases of Children, 62, 716-729.

PINTO, A., FAIZ, O., DAVIS, R., ALMOUDARIS, A. \& VINCENT, C. 2016. Surgical complications and their impact on patients' psychosocial well-being: a systematic review and meta-analysis. BMJ Open, 6.

POLESHUCK, E. L., KATZ, J., ANDRUS, C. H., HOGAN, L. A., JUNG, B. F., KULICK, D. I. \& DWORKIN, R. H. 2006. Risk factors for chronic pain following breast cancer surgery: a prospective study. The Journal of Pain, 7, 626-634.

SALISBURY, M. H., LAMONTAGNE, L. L., HEPWORTH, J. T. \& COHEN, F. 2007. Parents' SelfIdentified Stressors and Coping Strategies During Adolescents' Spinal Surgery Experiences. Clinical Nursing Research, 16, 212-230.

SVAVARSDOTTIR, E. K. 2005. Caring for a child with cancer: a longitudinal perspective. Journal of Advanced Nursing, 50, 153-161.

TAYLOR, M. R. \& O'CONNOR, P. 1989. Resident parents and shorter hospital stay. Archives of Disease in Childhood, 64, 274-276.

THOMPSON, D. G. \& TIELSCH-GODDARD, A. 2014. Improving Management of Patients With Autism Spectrum Disorder Having Scheduled Surgery: Optimizing Practice. Journal of Pediatric Health Care, 28, 394-403.

VERNON, D. T. 1965. The psychological responses of children to hospitalization and illness: A review of the literature, CC Thomas.

VETSCH, J., RUEEGG, C. S., GIANINAZZI, M. E., BERGSTRÄSSER, E., VON DER WEID, N. X. \& MICHEL, G. 2015. Information needs in parents of long- term childhood cancer survivors. Pediatric blood \& cancer, 62, 859-866.

WAKEFIELD, C. E., BUTOW, P., FLEMING, C. A., DANIEL, G. \& COHN, R. J. 2012. Family information needs at childhood cancer treatment completion. Pediatric blood \& cancer, 58, 621626.

WALKER, A. J., GEDALY-DUFF, V., MIASKOWSKI, C. \& NAIL, L. 2010. Differences in Symptom Occurrence, Frequency, Intensity, and Distress in Adolescents Prior to and One Week After the Administration of Chemotherapy. Journal of Pediatric Oncology Nursing, 27, 259-265. 
WARD, E., DESANTIS, C., ROBBINS, A., KOHLER, B. \& JEMAL, A. 2014. Childhood and adolescent cancer statistics, 2014. CA: A Cancer Journal for Clinicians, 64, 83-103.

WEI, H., ROSCIGNO, C. I., SWANSON, K. M., BLACK, B. P., HUDSON-BARR, D. \& HANSON, C. C. Parents' experiences of having a child undergoing congenital heart surgery: An emotional rollercoaster from shocking to blessing. Heart \& Lung: The Journal of Acute and Critical Care, $45,154-160$.

WILLIAMS, G., BELL, G., BUYS, J., MORIARTY, T., PATEL, A., SUNDERLAND, R., SHEPHERD, L., BROOKS, P. \& POLHILL, S. 2015. The prevalence of pain at home and its consequences in children following two types of short stay surgery: a multicenter observational cohort study. Pediatric Anesthesia, 25, 1254-1263.

WONG, M. Y. F. \& CHAN, S. W. C. 2006. The qualitative experience of Chinese parents with children diagnosed of cancer. Journal of Clinical Nursing, 15, 710-717.

YGGE, B. M. \& ARNETZ, J. E. 2004. A study of parental involvement in pediatric hospital care: implications for clinical practice. Journal of pediatric nursing, 19, 217-223.

ZELTZER, L. K., RECKLITIS, C., BUCHBINDER, D., ZEBRACK, B., CASILLAS, J., TSAO, J. C. I., LU, Q. \& KRULL, K. 2009. Psychological Status in Childhood Cancer Survivors: A Report From the Childhood Cancer Survivor Study. Journal of Clinical Oncology, 27, 2396-2404.

\section{FIGURE LEGENDS}

Table 1. Illustrative quotes from interviews with survivors and parents

Table 2. Clinical and demographic characteristics of participating survivors and parents of survivors

Figure 1. Participant recruitment process

Figure 2. Participant distress ratings

\section{SUPPLMENTARY TABLES}

Supplementary Table 1. Interview guide for survivors and parents

Supplementary Table 2. Themes used to guide qualitative data analysis

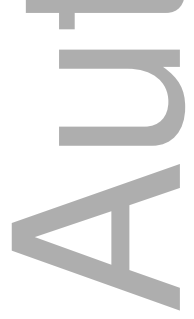


Table 1. Illustrative quotes from interviews with survivors and parents

\begin{tabular}{|c|c|}
\hline \multicolumn{2}{|c|}{ Preoperative period } \\
\hline $\begin{array}{l}\text { Survivors } \\
\text { "You don't know why you're there. You just kind of are in pain. People are just } \\
\text { prodding you. You have no idea why. So I think that in itself is quite confusing in a } \\
\text { traumatising sort of way... I was very very fearful... I developed a very very severe } \\
\text { fear to injections... I think it's got a lot of subconscious memories and some that have } \\
\text { been quite severely suppressed" (female Neuroblastoma survivor, aged } 1 \text { at } \\
\text { "You couldn't take it all in, it was too much... It was a lot of information to take in at } \\
\text { the one time" (male Brain cancer survivor, aged } 2 \text { at diagnosis) } \\
\text { "[staff] didn't really prepare me as much for the tumor surgery" (female Brain } \\
\text { cancer survivor, aged } 8 \text { at diagnosis). }\end{array}$ & $\begin{array}{l}\text { Parents } \\
\text { "He would scream and it would be hard... They're hungry, they don't understand, } \\
\text { they're thirsty. It's a nightmare" (mother of Retinoblastoma survivor aged } 1 \text { at } \\
\text { diagnosis). } \\
\text { "He hated blood pressure, there was a few needles and things that he had to have, } \\
\text { different medication. He hated those" (mother of Brian cancer survivor aged } 2 \text { at } \\
\text { diagnosis). } \\
\text { "You do worry beforehand [especially] the day of surgery when they're babies, } \\
\text { handing them over... You know that's a horrible feeling" (mother of } \\
\text { Hepatoblastoma survivor aged } 1 \text { at diagnosis). }\end{array}$ \\
\hline \multicolumn{2}{|c|}{ Intraoperative period } \\
\hline $\begin{array}{l}\text { Survivors } \\
\text { "I don't think anybody had told mum why [surgery] was so much longer...Probably } \\
\text { somebody coming and talking to her [would have helped]" (female Non-Hodgkins } \\
\text { lymphoma survivor, aged } 9 \text { at diagnosis). } \\
\text { "[My father] saw me [in hospital years later] and he actually burst into tears. I said } \\
\text { 'What's wrong with you?' ...He just said 'This just takes me back to when I was here } \\
\text { [while waiting]'... He just lost it. So I think that kind of illustrated to me how } \\
\text { distressing that would have been" (female Neuroblastoma survivor, aged } 1 \text { at }\end{array}$ & $\begin{array}{l}\text { Parents } \\
\text { "Time sort of takes on a different perspective when you're waiting for that sort of } \\
\text { thing to finish. This situation... is as upsetting as basically you can get... We were } \\
\text { never updated during the surgery" (father of Hepatoblastoma survivor aged } 2 \text { at } \\
\text { diagnosis). } \\
\text { "I didn't leave there. I paced up and down the hallway. The surgery was when } \\
\text { September } 11 \text { happened so we had all that going on in the background. Every } \\
\text { single TV, everything that was in our face the whole time. It was really surreal” } \\
\text { (mother of Hepatoblastoma survivor aged } 1 \text { at diagnosis). } \\
\text { "It's hard to know what to do during the surgery... You don't want to be too far }\end{array}$ \\
\hline
\end{tabular}

This article is protected by copyright. All rights reserved 




This article is protected by copyright. All rights reserved 


\begin{tabular}{|c|c|}
\hline $\begin{array}{l}\text { cancer itself but more importantly because of all the side effects of having surgery" } \\
\text { (female survivor, aged Neuroblastoma } 1 \text { at diagnosis) } \\
\text { "My surgeon... I'm still in contact with him even today. He's the best" (male } \\
\text { Hepatoblastoma survivor, aged } 1 \text { at diagnosis) }\end{array}$ & $\begin{array}{l}\text { because I'd wake up and my heart rate would be like } 120 \ldots \text { I still wake up at night } \\
\text { like that" (mother of Hepatoblastoma survivor, aged } 1 \text { at diagnosis). } \\
\text { "It stays with you - it will stay with you for the rest of your life... There's always } \\
\text { this constant fear that it might come back" (father of Pleuropulmonary Blastoma } \\
\text { survivor, aged } 3 \text { at diagnosis). } \\
\text { "We did get very well looked after. Even to this day, you walk into the hospital and } \\
\text { they just come running" (mother of Wilm's tumor survivor, aged } 5 \text { at diagnosis) }\end{array}$ \\
\hline
\end{tabular}

This article is protected by copyright. All rights reserved 
Table 2. Clinical and demographic characteristics of participating survivors and parents of survivors

\begin{tabular}{|c|c|c|}
\hline Characteristic & $\begin{array}{c}\text { Adult survivors } \\
\mathrm{n}=17(53 \%)\end{array}$ & $\begin{array}{l}\text { Parents of survivors } \\
\quad n=15(47 \%)\end{array}$ \\
\hline \multicolumn{3}{|l|}{ Survivor sex } \\
\hline Male & $7(41.2)$ & $8(53.3)$ \\
\hline Female & $10(58.8)$ & $7(46.7)$ \\
\hline \multicolumn{3}{|l|}{ Relationship to survivor } \\
\hline Father & NA & $4(26.7)$ \\
\hline Moth & NA & $11(73.3)$ \\
\hline \multicolumn{3}{|l|}{ Ethnic background } \\
\hline Australian/New Zealand & $9(53.0)$ & $11(73.3)$ \\
\hline European & $8(47.1)$ & $4(26.7)$ \\
\hline Asian & 0 & $1(6.7)$ \\
\hline \multicolumn{3}{|l|}{ Area of residence } \\
\hline Major City & $9(56.3)$ & $9(69.2)$ \\
\hline Inner/Outer regional & $7(43.8)$ & $4(30.8)$ \\
\hline \multicolumn{3}{|l|}{ Education } \\
\hline No post-school qualifications & $10(58.8)$ & $6(46.2)$ \\
\hline Post-school qualifications & $7(41.2)$ & $7(53.8)$ \\
\hline \multicolumn{3}{|l|}{ Employed } \\
\hline Yes & $10(58.8)$ & $13(86.7)$ \\
\hline No & $7(41.2)$ & $2(13.4)$ \\
\hline \multicolumn{3}{|l|}{ Income } \\
\hline$<$ AUD $\$ 60,000$ & $10(58.8)$ & $3(21.4)$ \\
\hline$>$ AUD $\$ 60,000$ & $7(41.2)$ & $11(78.6)$ \\
\hline \multicolumn{3}{|l|}{ Diagnosis } \\
\hline Lymphoma & $2(11.8)$ & 0 \\
\hline Brain & $4(23.5)$ & $3(30.0)$ \\
\hline Other & $11(64.7)$ & $7(70.0)$ \\
\hline \multicolumn{3}{|l|}{ Treatment received } \\
\hline Surgery & $17(100.0)$ & $15(100.0)$ \\
\hline Chemotherapy & $16(94.1)$ & $15(100.0)$ \\
\hline Radiotherapy & $8(50.0)$ & $8(53.3)$ \\
\hline Bone Marrow Transplant & $3(18.8)$ & $5(35.7)$ \\
\hline Other & $1(9.1)$ & $3(25.0)$ \\
\hline
\end{tabular}

This article is protected by copyright. All rights reserved 


\begin{tabular}{ccc}
\hline & Mean (SD) & Mean (SD) \\
\hline Age of survivor in years ${ }^{\ddagger}$ & $23.41(5.050)$ & $15.13(3.563)$ \\
Range & $16-33$ & $10-25$ \\
Age of parents in years & NA & $51.08(5.139)$ \\
Range & NA & $44-58$ \\
Age of child at time of surgery in years & $6.88(5.171)$ & $2.13(1.407)$ \\
Range & $0-15$ & $1-5$ \\
Time since treatment completion in years & $15.18(\mathrm{SD}=6.72)$ & $11.47(3.94)$ \\
Range & $5-27$ & $5-22$ \\
\hline
\end{tabular}

Abbreviations: n: Number of participants; NA: Not assessed, or not applicable; SD: Standard deviation

Numbers may not add up due to missing values.

${ }^{\dagger}$ According to Area of Remoteness Index Australia (ARIA) classifications. ${ }^{39}$

${ }^{*}$ Given cognitive impairments in some adult survivors or the time lapsed between questionnaire and interview completion, some survivors over 16 were represented by their parents in the interviews to ensure consistency across both stages of the study.

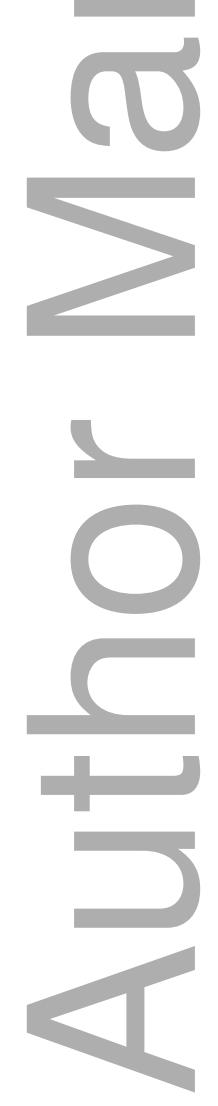




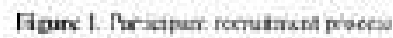

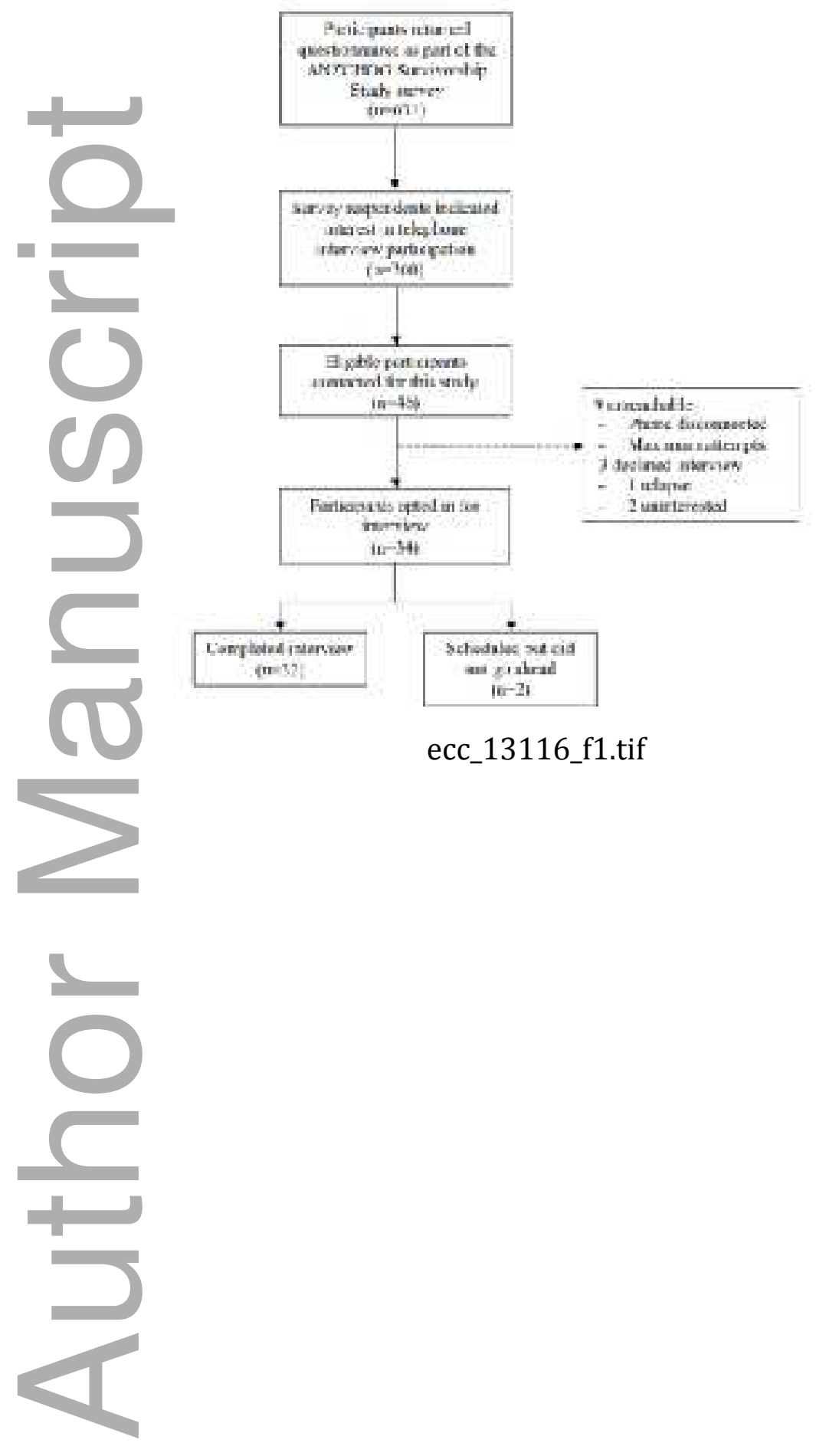

This article is protected by copyright. All rights reserved 
Figure 2. Futicpan cistics trikges

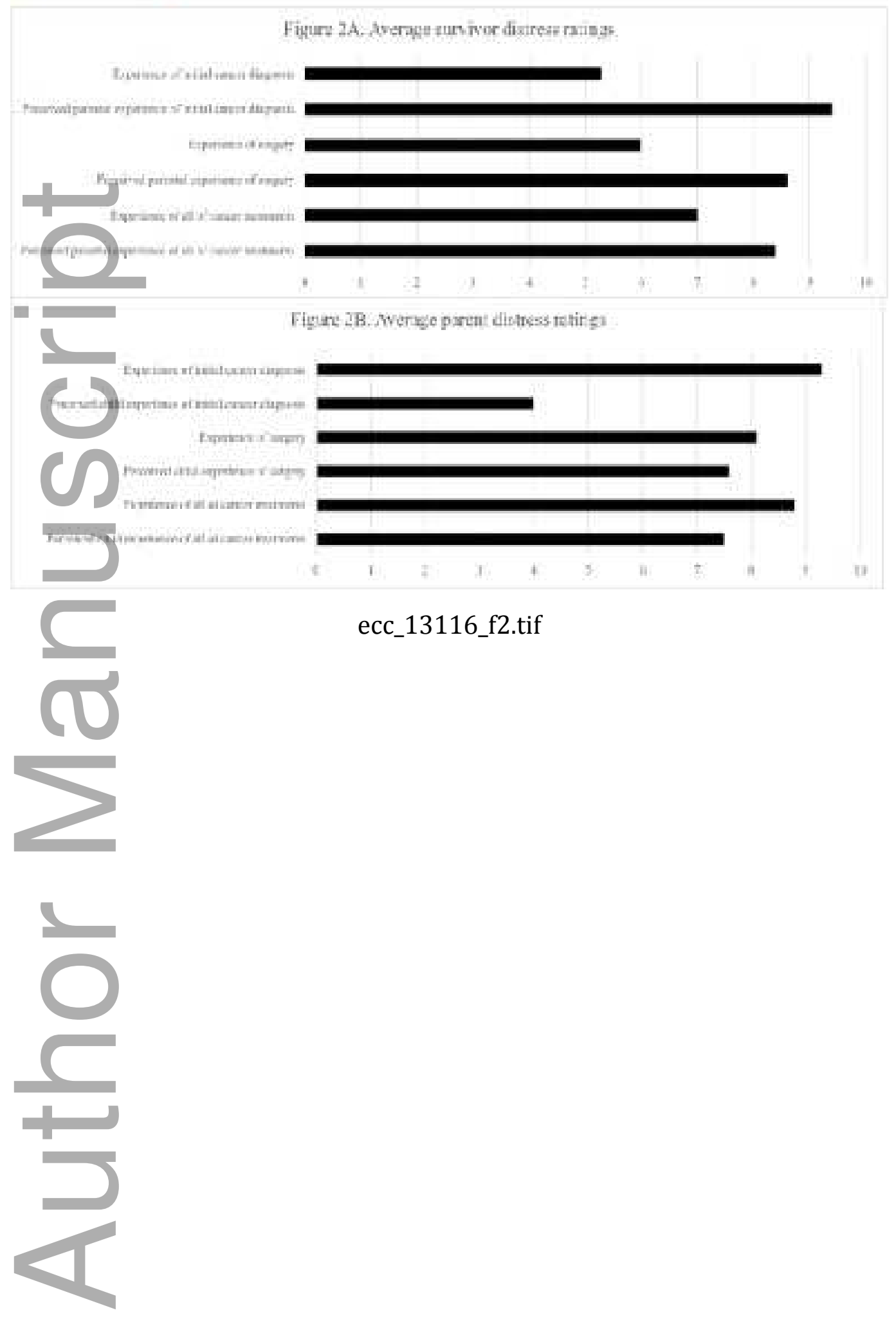

This article is protected by copyright. All rights reserved 


\section{University Library}

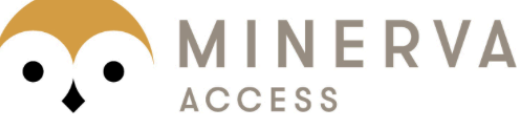

A gateway to Melbourne's research publications

Minerva Access is the Institutional Repository of The University of Melbourne

\section{Author/s:}

Gabriel, MG;Wakefield, CE;Vetsch, J;Karpelowsky, JS;Darlington, A-SE;Cohn, RJ;Signorelli, C;ANZCHOG Survivorship Study Group,

Title:

Paediatric surgery for childhood cancer: Lasting experiences and needs of children and parents.

Date:

2019-09

\section{Citation:}

Gabriel, M. G., Wakefield, C. E., Vetsch, J., Karpelowsky, J. S., Darlington, A. -S. E., Cohn, R. J., Signorelli, C. \& ANZCHOG Survivorship Study Group, (2019). Paediatric surgery for childhood cancer: Lasting experiences and needs of children and parents.. Eur J Cancer Care (Engl), 28 (5), pp.e13116-. https://doi.org/10.1111/ecc.13116.

Persistent Link:

http://hdl.handle.net/11343/285968 